\title{
Metabolic disturbances in patients with obstructive sleep apnoea syndrome
}

\author{
I.A. Harsch
}

ABSTRACT: The metabolic disturbances in patients with obstructive sleep apnoea syndrome (OSAS) include insulin resistance and elevated levels of pro-inflammatory cytokines and vascular adhesion molecules, as well as an elevation of hormones derived from the adipose tissue as leptin. These phenomena might, in part, be an explanation for the excess morbidity and mortality of OSAS patients concerning cardiovascular disease.

Several of these factors have been described as being independently associated with OSAS and not only related to its comorbidities, including obesity.

A promising approach to studying the metabolic phenomena in these OSAS patients would be to monitor patients before and during the course of continuous positive airway pressure therapy, as nocturnal sleep disturbances are treatable and may revert the impact of OSAS on the metabolic phenomena; however, patients do frequently (and unfortunately) maintain their body weight.

Although not confirmed by all investigations, a tendency towards an improvement in some of the above-mentioned metabolic parameters has been reported in several studies in obstructive sleep apnoea syndrome patients and may be reflected by the decreased occurrence of new cardiovascular events, the reduction of systolic blood pressure and the improvement of left ventricular systolic function.

KEYWORDS: Adiponectin, continuous positive airway pressure therapy, diabetes, insulin sensitivity, leptin, obstructive sleep apnoea syndrome

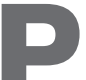

atients with obstructive sleep apnoea syndrome (OSAS) frequently suffer from cardiovascular disease (CVD) [1-3] and have excess mortality caused by CVD [4-6]. Many investigators have reported that the link between OSAS and cardiovascular events may be related to concomitant diseases, i.e. obesity, diabetes mellitus, hypertension, hypothyroidism and hyperlipidaemia, and not to OSAS itself. There is a growing body of evidence that has characterised the metabolic disturbances associated with OSAS and atherosclerosis more precisely, as well as the effect of nasal continuous airway positive pressure (CPAP) therapy in these OSAS patients. The results are indicative that some metabolic disturbances are an independent phenomenon and are risk factors linked to OSAS and not to the concomitant diseases. The current article reviews some of the studies about metabolic phenomena, such as insulin resistance, hypercytokinaemia and fat-derived hormones, in OSAS, as well as the impact of nasal CPAP therapy on these phenomena.

\section{INSULIN RESISTANCE}

Insulin (in)sensitivity or insulin resistance has been among the major metabolic features of
OSAS to be intensively studied. The presence of insulin resistance has been repeatedly reported in patients with OSAS [7]. Unfortunately, insulin resistance is not uncommon in the general population and is associated with obesity, immobility, type 2 diabetes and several other conditions. Obesity is particularly present in OSAS, at least in those of Caucasian origin [8]. STOOHS et al. [7] concluded that insulin resistance in patients with OSAS was determined by the typical obesity of the patients alone. However, IP et al. [9] were able to demonstrate that obesity was the major determinant of insulin resistance in a group of 270 patients with OSAS, but that the parameters of sleep-disordered breathing (SDB; apnoea/ hypopnoea index $(\mathrm{AHI})$, minimal oxygen saturation) were also independent determinants of insulin resistance by stepwise multiple linear regression analysis. PUNJABI et al. [10] also demonstrated an association between an increasing $\mathrm{AHI}$ and insulin resistance independent of obesity in mildly obese males. Under the assumption of insulin resistance as an atherogenic risk factor [11, 12], at least in part mediated by OSAS, it would be interesting to study whether the adequate treatment of OSAS improves insulin sensitivity.
CORRESPONDENCE

I.A. Harsch

Head of Division of Endocrinology and Metabolism

Medical Dept I

Friedrich-Alexander University

Erlangen-Nuremberg

Ulmenweg 18

D-91054 Erlangen

Germany.

Fax: 4991318530231

E-mail: igor.harsch@uk-erlangen.de

STATEMENT OF INTEREST

The present article was presented as part of the international symposim "Respiratory somnology: a clinical update", sponsored by GlaxoSmithKline, Belgium. 
Preceding studies on the effect of nasal CPAP on insulin sensitivity had conflicting results. A study by BROOKS et al. [13] showed a tendency to improved insulin sensitivity after 4 months of CPAP treatment measured by hyperinsulinaemic euglycaemic clamp in severely obese and diabetic patients; however, two other investigations could not confirm this result in nondiabetic patients with OSAS [14, 15]. Since measuring insulin sensitivity with the hyperinsulinaemic euglycaemic clamp technique [16] is exceedingly laborious, one problem with these investigations was the small number of patients, which may not offer enough statistical power to detect significant associations between insulin sensitivity and indices of SDB. Furthermore, with the reassessment of insulin sensitivity carried out 2-4 months after the onset of nasal CPAP treatment, other factors influencing insulin sensitivity (weight, changes in body fat distribution, treatment of concomitant diseases, changes in dietary behaviour, smoking, alcohol consumption and physical activity) are also of considerable importance.

Repetitive hypoxias have been demonstrated to cause insulin resistance [17]. An attractive hypothesis as to why insulin resistance in OSAS occurs is that insulin resistance in OSAS is not only caused by the hypoxaemia, but is at least partly also induced by increased sympathetic drive as a consequence of the repetitive arousals [18]; however, by reducing or correcting the hypoxaemias and the nocturnal stress caused by SDB, this should be quickly reversible by nasal CPAP therapy. Under this assumption, the present author was able to demonstrate an improvement in insulin sensitivity as early as 2 days after onset of effective CPAP therapy in most patients (thus, ruling out other confounders such as weight loss; fig. 1) that was maintained after 3 and 30 months (30-month data presently unpublished). There was a tendency to a better effect of nasal CPAP therapy, the less obese the patients were [19]. Of course, factors such as the impact of the hyperinsulinaemic euglycaemic clamp on sympathetic activity have to be taken into consideration [20], as well as the considerable insulin resistance in the present author's study group, but the most important question still open is whether the improvement of a surrogate parameter, such as insulin sensitivity, has a clinical impact, considering the disappointing finding of the present author and many of the already mentioned studies, that the body weight of the patients did not change.

\section{OSAS, INSULIN RESISTANCE AND GLYCAEMIC CONTROL IN PATIENTS WITH TYPE 2 DIABETES}

Patients with type 2 diabetes are frequently obese, as are patients with OSAS. It is therefore not surprising that a significant number of patients suffer from both conditions [21-23]. A common feature of both diseases is insulin resistance. In diabetic patients, the insulin resistance can be assumed to have another quality of impact on metabolism, since, together with other factors that are partly genetically determined, insulin resistance is able to disturb the glycaemic balance and cause hyperglycaemia. As already mentioned, there is a growing body of data suggesting that the insulin sensitivity in nondiabetic patients with OSAS can be improved by nasal CPAP therapy. Given this fact, it seems possible that the glycaemic control in patients with diabetes and OSAS could also be improved. BROOKS et al. [13] demonstrated an improvement in insulin sensitivity (via a clamp study) in nine severely obese type 2 diabetic patients after 4 months of nasal CPAP therapy; however, no improvement in glycaemic control was observed (as measured via haemoglobin (Hb)A1c levels). The present author's studies in type 2 diabetic patients with good glycaemic control confirmed these (disappointing) findings [24]. However, BABU et al. [25] demonstrated an improvement of the $\mathrm{HbA} 1 \mathrm{c}$ levels, especially in a subgroup of 25 patients with bad glycaemic control ( $\mathrm{HbA} 1 \mathrm{c} 9.2$ versus $8.6 \%$ ), after $\sim 83$ days of nasal CPAP therapy; these results were recently confirmed by HASSABALLA et al. [26] in moderately controlled patients (7.8 versus $7.3 \%$ ).

The patients of BROOKS et al. [13] were severely obese and a huge amount of comorbidity can be assumed. Thus, to summarise the results of the present studies, an improvement of insulin sensitivity in patients with diabetes is demonstrated, which, provided that there are not too many other comorbidities present to overrule this effect, also helps to improve glycaemic control, especially in insufficiently controlled type 2 diabetic patients.

\section{PRO-INFLAMMATORY CYTOKINES AND ADHESION MOLECULES IN OSAS}

The excellent effects of nasal CPAP treatment on the improvement of daytime vigilance and activity need no further comment; however, many of the metabolic effects are still awaiting further clarification. With the current view of atherosclerosis as a consequence of subclinical inflammation [27-29], it would be interesting to study surrogate parameters of subclinical inflammation, as well as thrombocyte activation in patients with OSAS.

Highly sensitive C-reactive protein (hsCRP), described as being increased in OSAS [30], was recently introduced as a cardiovascular risk factor in the American Heart Association (AHA) guidelines [31]. YOKOE et al. [32] reported a correction of elevated hsCRP by nasal CPAP therapy in a group of 30 Japanese patients with OSAS (the body mass index (BMI) in 13

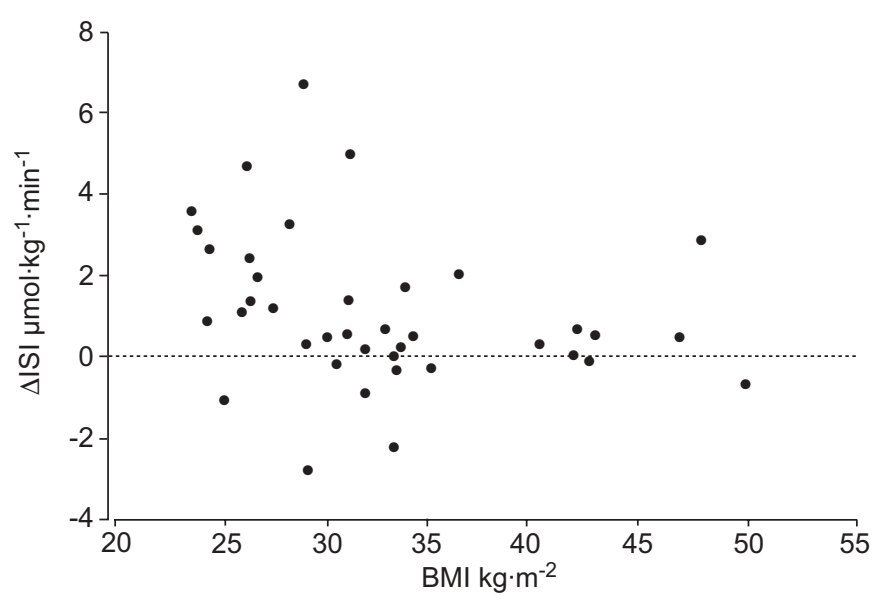

FIGURE 1. Changes in insulin sensitivity index $(\Delta|S|)$ between baseline and 2 days after onset of continuous positive airway pressure treatment. The changes are significantly different for the whole group $(p=0.003)$. Furthermore, the degree of change is significantly different in the patients with body mass index (BMI) $<30 \mathrm{~kg} \cdot \mathrm{m}^{-2}$, but not in the patients with $\mathrm{BMI}>30 \mathrm{~kg} \cdot \mathrm{m}^{-2}$. 
of the patients with mild OSAS was $25.1 \mathrm{~kg} \cdot \mathrm{m}^{-2}$, and in 17 with moderate-to-severe OSAS was $31.7 \mathrm{~kg} \cdot \mathrm{m}^{-2}$ ). The findings of an elevated CRP in patients with OSAS were reproduced by KOKTURK et al. [33], especially in patients with OSAS and CVD, but were contradicted. GUILLEMINAULT et al. [34] found the CRP levels in 156 subjects with OSAS significantly correlated with the BMI, but not the indices of the OSAS. In a recent study (personal communication, I.A. Harsch, Medizinische Klinik 1 mit Poliklinik, Universitätsklinikum Erlangen, Erlangen, Germany), a correction of elevated CRP levels was not observed after 3 months of CPAP therapy in a group of patients with higher BMIs and with more comorbidities than in the group of YOKOE et al. [32].

Such observations were also found to be the case for interleukin (IL)-6, classed as an "endocrine" cytokine as it mediates inflammatory responses at sites distinct from its origin; levels of IL-6 were described as increased in OSAS patients by ҮОКОЕ et al. [32]. Cytokines, such as IL-6, induce the hepatic production of acute-phase proteins, such as hsCRP and serum amyloid-A [35]. No decrease of IL-6 levels were observed in the present author's study group after 3 months of nasal CPAP therapy (personal communication, I.A. Harsch, Medizinische Klinik 1 mit Poliklinik, Universitätsklinikum Erlangen, Erlangen, Germany). In an analysis by IMAGAWA et al. [36] of patients with severe OSAS ( $n=110)$, IL-6 was not even described as increased in the patients. Positive associations between IL-6 levels and measures of obesity have already been described by VGONTZAS et al. [37], who also found IL-6 elevated in OSAS (table 1).

Tumour necrosis factor (TNF)- $\alpha$ is another pleiotrophic proinflammatory cytokine that has been studied extensively in OSAS. Apart from its pro-inflammatory effects, it is also involved in all steps of the development of atherosclerosis via activation of adhesion and chemoattractant proteins. Unfortunately, the study situation is confusing and controversial. VGONTZAS et al. [38] described the concentration of TNF- $\alpha$ as being significantly elevated in patients with OSAS (and narcolepsy), and being higher in obese males with OSAS than in obese males without OSAS [38, 39]. These findings could not be confirmed in a study of 110 Japanese patients with OSAS [36], whereas a more recent study described an elevation of TNF- $\alpha$ in serum and monocyte cell cultures according to the degree of OSAS, which was decreased by nasal CPAP $(n=24$; 1 month of nasal CPAP therapy) [39].

TAZAKI et al. [40] analysed the levels and activity of matrix metalloproteinase- 9 in 44 patients with OSAS. The concentration of these zinc-containing endoproteases is typically increased in the remodelling processes of atherosclerosis and myocardial infarction. Their levels were decreased by 1 month of nasal CPAP therapy in OSAS patients with a BMI of $\sim 29 \mathrm{~kg} \cdot \mathrm{m}^{-2}$, i.e. in patients who were not obese. It would be highly interesting to study whether these effects also occur in obese patients.

As can easily be seen, one of the main problems in the judgement of metabolic phenomena in OSAS, as well as the metabolic impact of nasal CPAP therapy in these patients, seems to be to disentangle the metabolic phenomena caused by obesity from the metabolic phenomena that lie within OSAS itself, an almost insurmountable problem, since the patients, at least those from European and American studies, are typically obese. Furthermore, these patients often suffer from other comorbidities, such as hypertension, pathological glucose tolerance or even diabetes, which can also alter metabolic phenomena and their response to nasal CPAP treatment. In particular, obesity alone seems to be an extremely important contributor to systemic inflammation. Correlations between hsCRP and BMI have been demonstrated [41], which also account for IL-6 and TNF- $\alpha$ [37]. Taken together, many studies suggest that the systemic inflammatory state in patients with OSAS is, at least in part, maintained by OSAS itself. One of the main problems in the interpretation of these data is that the pro-inflammatory cytokines and adhesion molecules are not specific for OSAS, and their sometimes elevated levels may also be related to other coexisting diseases, given the high incidence of comorbidities and obesity in these patients. It would go beyond the scope of the present article to list all surrogate parameters of subclinical inflammation and endothelial and thrombocyte activation that have been analysed in the sera of patients with OSAS, but there seems to be a tendency for an effect of the nasal CPAP treatment of OSAS to decrease systemic subclinical inflammation the leaner the subjects are; this would especially account for the results of the typically leaner Japanese patients in the studies described $[32,40]$. This perhaps makes obesity the main culprit for systemic inflammation,

TABLE 1 Surrogate parameters of subclinical inflammation in patients with obstructive sleep apnoea syndrome (OSAS)

\begin{tabular}{|c|c|c|c|c|c|}
\hline & IL-6 & IL-6 + CRP\# & IL-6 & CRP & CRP \\
\hline First author [Ref.] & VGONTZAS [37] & YOKOE [32] & IMAGAWA [36] & GUILLEMINAULt [34] & KoKTURK [33] \\
\hline Patients n & 12 & 30 & 110 & 156 & $\begin{array}{l}94 \text { (OSAS with CVD); } \\
56 \text { (OSAS without CVD }\end{array}$ \\
\hline Mean BMI & 40.5 & 27.5 & 26 & 29.4 & 32 \\
\hline
\end{tabular}

IL: interleukin; CRP: C-reactive protein; CVD: cardiovascular disease; BMI: body mass index; +: significant positive correlation; -: no correlation; AHI: apnoea/hypopnoea index. ${ }^{\#}$ : improvement of these parameters occurred after 1 month of nasal continuous positive airway pressure therapy. 
and OSAS a lesser contributor; this is also true for insulin sensitivity [19].

\section{HORMONES INVOLVED IN CALORIC INTAKE AND ENERGY REGULATION}

Leptin (derived from the Greek word "leptos", which means thin) is the protein product of the $o b$ (obesity) gene, and adipocytes are the main source of this 167 amino acid, $16-\mathrm{kDa}$ hormone. The effect of leptin is best characterised as the regulation of energy expenditure and food intake, mainly via hypothalamic effects. Apart from the regulation of food intake and energy expenditure, further effects of leptin include angiogenesis and haematopoiesis, as well as effects on carbohydrate and lipid metabolism. Leptin correlates with fat stores and responds to changes in energy balance [42]. Through a central impact in the hypothalamus, leptin can suppress feeding and increase energy expenditure, thereby resulting in weight loss. In obesity, increased leptin levels are seen, suggesting the development of insensitivity to this polypeptide. Leptin circulates in the serum in both a free form and a form bound to a carrier protein, with the balance between free and bound leptin being a potential regulator of leptin bioavailability [43]. Leptin receptors are distributed in both peripheral and central nervous systems. Peripheral expression sites include tissues, such as lung, kidney, liver, pancreas, adrenals, ovaries, haematopoietic stem cells and skeletal muscle. It is not surprising that leptin levels are elevated in the typically obese patients with OSAS, since the increased fat mass correlates with the plasma leptin levels [44].

In humans, it is not clear whether leptin might also interact with respiratory functions. Females, even after adjusting for body fat mass, have higher leptin levels than males and a lower incidence of OSAS. Furthermore, patients with OSAS present higher leptin levels in comparison with obese controls without disturbances of respiratory function, and leptin levels significantly decrease after nasal CPAP treatment, irrespective of weight changes.

It has been demonstrated that patients with OSAS have significantly higher levels of serum leptin than comparably obese persons, excluding SDB patients $[45,46]$. In both studies $[45,46]$, OSAS patients were compared with BMI-matched controls. The serum leptin levels were $9.18 \pm 4.24 \mathrm{mg} \cdot \mathrm{mL}^{-1}$ versus $6.54 \pm 3.81 \mathrm{ng} \cdot \mathrm{mL}^{-1}$ [45] and 12.7 (range $10.7-14.9$ ) versus $4.4(3.6-5.4) \mathrm{ng} \cdot \mathrm{mL}^{-1}[46]$.

It is not surprising that a number of authors have tried to establish a direct relationship between serum leptin and the severity of respiratory dysfunction in OSAS. PHILLIPS et al. [47] described a positive correlation between leptin and AHI in subjects with newly diagnosed OSAS and no concomitant diseases, a finding that was reproduced by CIFTCI et al. [48]. A significant inverse correlation $(\mathrm{r}=-0.73 ; \mathrm{p}<0.001)$ between plasma soluble leptin receptor and AHI (also after correction for BMI) has also been demonstrated in a patient group free of concomitant diseases [49]. In a recent study, serum leptin level concentrations (log-transformed) were found to be significantly correlated with AHI $(\mathrm{r}=0.39)$, but failed to reach significance after correction for BMI and body fat in a group with numerous comorbidities [50]. The latter finding is in accordance with the present author's results [46], which show a positive correlation between serum leptin and AHI $(r=0.421)$ that is lost after correction for BMI. The frequency of arterial hypertension in the present author's patient group was high [46] in comparison with nonhypertensive patients in the two studies by PHILlips et al. [47] and MANZELla et al. [49]. A possible explanation might be that the present author's patient group [46] and that of SCHÄFER et al. [50] are too different in terms of comorbidities, also possibly confounding a relationship between AHI and serum leptin levels. However, it must be kept in mind that leptin levels in patients with OSAS are not only a possible expression of respiratory function or dysfunction, but also of numerous metabolic processes other than appetite and energy homeostasis. Body fat alone accounts for $50-60 \%$ of leptin's variability and other factors, such as age, sex and hormonal and cytokine levels, also contribute to the regulation of leptin levels [51]. All these aspects have made it impossible to clarify if leptin might also exert a promotion of respiratory drive in humans, as has been clearly demonstrated in animal models $[52,53]$.

The involvement of ghrelin, another stomach-derived hormone concerned with caloric intake and energy regulation, in (pro)respiratory properties also needs to be investigated in larger studies than those carried out to date [46, 48].

\section{THE ROLE OF ADIPONECTIN IN OSAS}

Adiponectin is a polypeptide consisting of 244 amino acids. Adiponectin plays a very important role among fat-derived hormones due to its putative insulin-sensitising and antiatherogenic properties [54,55]. Serum adiponectin concentrations are predominantly determined by visceral fat accumulation, which plays a more important role than subcutaneous fat accumulation with respect to cardiovascular risk [56]. Furthermore, adiponectin reduces the plasma concentration of fatty acids directly by accelerating fatty acid oxidation and indirectly by increasing the expression of proteins involved in fatty acid metabolism. Adiponectin also improves glucose tolerance by increasing insulin sensitivity [57]. Serum adiponectin levels are decreased in obese persons, as well as in type 2 diabetic patients. Due to its putative anti-inflammatory and insulin-sensitising properties, especially via an inhibition of differentiation of fat cells, with the pre-adipocyte as an important source of pro-inflammatory cytokines, adiponectin protects against the development of type 2 diabetes, as well as against atherosclerosis [58].

It is not surprising that the adiponectin levels have already been studied in patients with OSAS, but the results are conflicting. In a study by the present author [59] of 30 patients with OSAS, it was possible to demonstrate a small decrease in adiponectin serum levels that returned to baseline levels after 3 months of treatment. In these patients, the insulin sensitivity had significantly improved 2 days and 3 months after the onset of nasal CPAP therapy. The increase of insulin sensitivity was more pronounced in patients with the highest adiponectin levels at baseline after adjustment for body fat. During treatment, changes in adiponectin levels were highly predictable by the insulin sensitivity index. WOLK et al. [60] described the plasma adiponectin levels to be elevated in otherwise healthy subjects with OSAS $(n=35)$ compared with subjects without OSAS $(n=33)$; thus, adiponectin levels are unlikely to explain an association between OSAS and the cardiovascular 
complications of sleep disorders. However, in 66 (lean) Chinese patients with OSAS compared with 20 BMI-matched controls, the adiponectin levels were lower in the OSAS group [61], although the adiponectin serum levels were measured with the same assays in all studies. In a recent Japanese study [62], plasma adiponectin levels were not different between mild, moderate and severe OSAS patient groups. The plasma adiponectin levels were correlated with the insulin sensitivity of these patients, as calculated using the Homeostasis Model Assessment, which confirms the results of the present author's study [59]. However, although plasma adiponectin was an independent determinant of insulin sensitivity in OSAS patients, plasma adiponectin was more closely related to obesity than to sleep apnoea. The disentanglement of the effects of body weight/body fat content from the direct effects of OSAS also persists in the study of the role of adiponectin in sleep apnoea.

\section{CONCLUSIONS}

In conclusion, there is a growing body of evidence that some of the metabolic phenomena present in patients with obstructive sleep apnoea syndrome are not only related to comorbidities, especially the typical obesity of the patients, but are also, at least to some extent, a consequence of obstructive sleep apnoea syndrome itself. Some of these phenomena could be related to sympathetic activation by repetitive hypoxia and arousals in these patients, since the adequate nasal continuous positive airway pressure treatment was reported to improve insulin sensitivity and glycaemic control, as well as to decrease proinflammatory cytokines and adhesion molecules, at least in some studies. These results cannot be confirmed in all studies, especially since the impact of obesity may sometimes overrule the effect of continuous positive airway pressure therapy on such phenomena. However, there are encouraging findings that the improvement of the metabolic situation of patients with obstructive sleep apnoea syndrome does have positive clinical consequences: it was recently demonstrated that continuous positive airway pressure treatment is able to lower blood pressure [63], although it must be considered that many patients in this study were not hypertensive by definition [64]. Furthermore, in medically treated patients with heart failure, continuous positive airway pressure treatment reduces systolic blood pressure and improves left ventricular systolic function [65]. There are also data indicating that the treatment of obstructive sleep apnoea syndrome in patients with coronary heart disease decreases the occurrence of new cardiovascular events $[66,67]$.

\section{REFERENCES}

1 Fletcher EC. The relationship between systemic hypertension and obstructive sleep apnoea: facts and theory. Am J Med 1995; 98: 118-128.

2 Grunstein RR. Metabolic aspects of sleep apnoea. Sleep 1996; 19: Suppl. 10, S218-S220.

3 Stoohs RA, Guilleminault C. Cardiovascular changes associated with obstructive sleep apnoea syndrome. J Appl Physiol 1992; 72: 583-589.

4 Veale D, Chailleux E, Hoorelbeke-Ramon A, et al. Mortality of sleep apnoea patients treated by nasal continuous positive airway pressure registered in the ANTADIR observatory. Association Nationale pour le Traitement A
Domicile de l'Insuffisance Respiratoire chronique. Eur Respir J 2000; 15: 326-331.

5 Lavie P, Lavie L, Herer P. All-cause mortality in males with sleep apnoea syndrome: declining mortality rates with age. Eur Respir J 2005; 25: 514-520.

6 Noda A, Okada T, Yasuma F, Sobue T, Nakashima N, Yokota M. Prognosis of the middle-aged and aged patients with obstructive sleep apnoea syndrome. Psychiatry Clin Neurosci 1998; 52: 79-85.

7 Stoohs RA, Facchini F, Guilleminault C. Insulin resistance and sleep disordered breathing in healthy humans. Am J Respir Crit Care Med 1996; 154: 170-174.

8 Barcelo A, Barbe F, Llompart E, et al. Neuropeptide Y and leptin in patients with obstructive sleep apnoea syndrome: role of obesity. Am J Respir Crit Care Med 2005; 171: 183-187.

9 Ip MS, Lam B, Ng MMT, Lam WK, Tsang KWT, Lam KSL. Obstructive sleep apnoea is independently associated with insulin resistance. Am J Respir Crit Care Med 2002; 165: 670-676.

10 Punjabi NM, Sorkin JD, Karzel LI, Goldberg AP, Schwartz AR, Smith PL. Sleep-disordered breathing and insulin resistance in middle-aged and overweight men. Am J Respir Crit Care Med 2002; 165: 677-682.

11 Despres J-P, Lamarche B, Mauriege P, et al. Hyperinsulinemia as an independent risk factor for ischemic heart disease. $N$ Engl J Med 1996; 334: 952-957.

12 Fontbonne A, Charles MA, Thibult N, et al. Hyperinsulinemia as a predictor of coronary heart disease mortality in a healthy population: the Paris Prospective study, 15-year follow-up. Diabetologia 1991; 34: 356-361.

13 Brooks B, Cistulli PA, Borkman M, et al. Obstructive sleep apnoea in obese noninsulin-dependent diabetic patients: effect of continuous positive airway pressure treatment on insulin responsiveness. J Clin Endocrinol Metab 1994; 79: 1681-1685.

14 Saarelainen S, Lahtela J, Kallonen E. Effect of nasal CPAP treatment on insulin sensitivity and plasma leptin. J Sleep Res 1997; 6: 146-147.

15 Smurra M, Philip P, Taillard J, Guilleminault C, Bioulac B, Gin H. CPAP treatment does not affect glucose-insulin metabolism in sleep apneic patients. Sleep Med 2001; 2: 207-213.

16 DeFronzo RA, Tobin JD, Andres R. Glucose clamp technique: a method for quantifying insulin secretion and resistance. Am J Physiol 1979; 237: E214-E223.

17 Braun B, Rock PB, Zamudio S, et al. Women at altitude: short-term exposure to hypoxia and/or alpha1-adrenergic blockade reduces insulin sensitivity. J Appl Physiol 2001; 91: 623-631.

18 Coy TV, Dimsdale JE, Ancoli IS, Clausen J. Sleep apnoea and sympathetic nervous system activity: a review. J Sleep Res 1996; 5: 42-50.

19 Harsch IA, Pour Schahin S, Radespiel-Tröger M, et al. Continuous positive airway pressure treatment rapidly improves insulin sensitivity in patients with obstructive sleep apnoea syndrome. Am J Respir Crit Care Med 2004; 169: 156-162.

20 Punjabi NM. Improvement of metabolic function in sleep apnoea: the power of positive pressure. Am J Respir Crit Care Med 2004; 169: 139-140. 
21 Katsumata K, Okada T, Miyao M, Katsumata Y. High incidence of sleep apnoea syndrome in a male diabetic population. Diabetes Res Clin Pract 1991; 13: 45-51.

22 Ficker JH, Dertinger SH, Siegfried W, et al. Obstructive sleep apnoea and diabetes mellitus: the role of cardiovascular autonomic neuropathy. Eur Respir J 1998; 11: 14-19.

23 Strohl KP. Diabetes and sleep apnoea. Sleep 1996; 19: Suppl. 10, S225-S228.

24 Harsch IA, Schahin SP, Brückner K, et al. The effect of continuous positive airway pressure treatment on insulin sensitivity in patients with obstructive sleep apnoea syndrome and type 2 diabetes. Respiration 2004; 71: 252-259.

25 Babu AR, Herdegen J, Fogelfeld L, Shott S, Mazzone T. Type 2 diabetes, glycemic control, and continuous positive airway pressure in obstructive sleep apnoea. Arch Intern Med 2005; 165: 447-452.

26 Hassaballa HA, Tulaimat A, Herdegen JJ, Mokhlesi B. The effect of continuous positive airway pressure on glucose control in diabetic patients with severe obstructive sleep apnoea. Sleep Breath 2005; 9: 176-180.

27 Ross R. Atherosclerosis - an inflammatory disease. N Engl J Med 1999; 340: 115-126.

28 Ridker PM, Hennekens CK, Buring JE, Rifai N. C-reactive protein and other markers of inflammation in the prediction of cardiovascular disease in women. $N$ Engl J Med 2000; 342: 836-843.

29 Danesh J, Whincup P, Walker M, et al. Low grade inflammation and coronary heart disease: prospective study and updated meta-analyses. BMJ 2000; 321: 199-204.

30 Shamsuzzaman ASM, Winicki M, Lanfranchi P, et al. Elevated C-reactive protein in patients with obstructive sleep apnoea. Circulation 2002; 105: 2462-2464.

31 Pearson TA, Mensah GA, Alexander RW, et al. Markers of inflammation and cardiovascular disease: application to clinical and public health practice: A statement for healthcare professionals from the Centers for Disease Control and Prevention and the American Heart Association. Circulation 2003; 28: 499-511.

32 Yokoe T, Minoguchi K, Matsuo H, et al. Elevated levels of C-reactive protein and interleukin-6 in patients with obstructive sleep apnoea syndrome are decreased by nasal continuous positive airway pressure. Circulation 2003; 107: 1129-1134.

33 Kokturk O, Ciftci TU, Mollarecep E, Ciftici B. Elevated $\mathrm{C}$-reactive protein levels and increased cardiovascular risk in patients with obstructive sleep apnoea syndrome. Int Heart J 2005; 46: 801-809.

34 Guilleminault C, Kirisoglu C, Ohayon MM. C-reactive protein and sleep-disordered breathing. Sleep 2004; 27: 1507-1511.

35 Svatikova A, Wolk R, Shamsuzzaman AS, Kara T, Olson EJ, Somers VK. Serum amyloid A in obstructive sleep apnoea. Circulation 2003; 108: 1451-1454.

36 Imagawa S, Yamaguchi Y, Ogawa K, et al. Interleukin-6 and tumour necrosis factor- $\alpha$ in patients with obstructive sleep apnoea-hypopnoea syndrome. Respiration 2004; 71: 24-29.

37 Vgontzas AN, Papanicolaou DA, Bixler EO, Kales A, Tyson K, Chrousos GP. Elevation of plasma cytokines in disorders of excessive daytime sleepiness: role of sleep disturbance and obesity. J Clin Endocrinol Metab 1997; 82 1313-1316.

38 Vgontzas AN, Papanicolaou DA, Bixler EO. Sleep apnoea and daytime sleepiness and fatigue: relation to visceral obesity, insulin resistance, and hypercytokinemia. J Clin Endocrinol Metab 2000; 85: 1151-1158.

39 Minoguchi K, Tazaki T, Yokoe T, et al. Elevated production of tumour necrosis factor- $\alpha$ by monocytes in patients with obstructive sleep apnoea syndrome. Chest 2004; 126: 1473-1479.

40 Tazaki T, Minoguchi K, Yokoe T, et al. Increased levels and activity of matrix metalloproteinase- 9 in obstructive sleep apnoea syndrome. Am J Respir Crit Care Med 2004; 170: 1354-1359.

41 Visser M, Bouter LM, McQuillan GM, et al. Elevated C-reactive protein levels in overweight and obese adults. JAMA 1999; 282: 2131-2135.

42 Ahima RS, Flier JS. Leptin. Annu Rev Physiol 2000; 62: 413-437.

43 Sinha M, Opentanova I, Ohannesian JP, et al. Evidence of free and bound leptin in human circulation. Studies in lean and obese subjects and during short-term fasting. J Clin Invest 1996; 98: 1277-1282.

44 Considine RV, Sinha MK, Heiman ML, et al. Serum immunoreactive leptin concentrations in normal-weight and obese humans. N Engl J Med 1996; 334: 292-295.

45 Chin K, Shinizu K, Nakamura T, et al. Changes in intraabdominal visceral fat and serum leptin levels in patients with obstructive sleep apnoea syndrome following nasal continuous positive airway pressure therapy. Circulation 1999; 100: 706-712.

46 Harsch IA, Konturek PC, Koebnick C, et al. Leptin and ghrelin levels in patients with OSA - effect of CPAP treatment. Eur Respir J 2003; 22: 1-7.

47 Phillips BG, Kato M, Narkiewicz K, Choe I, Somers VK. Increases in leptin levels, sympathetic drive, and weight gain in obstructive sleep apnoea. Am J Physiol Heart Circ Physiol 2000; 279: 234-237.

48 Ciftci TU, Kokturk O, Bukan N, Bilgihan A. Leptin and ghrelin levels in patients with obstructive sleep apnoea syndrome. Respiration 2005; 72: 395-401.

49 Manzella D, Prillo M, Razzino T, et al. Solubile leptin receptor and insulin resistance as determinant of sleep apnoea. Int J Obesity 2002; 26: 370-375.

50 Schäfer H, Pauleit D, Sudhop T, Gouni-Berthold I, Ewig S, Berthold HK. Body fat distribution, serum leptin, and cardiovascular risk factors in men with obstructive sleep apnoea. Chest 2002; 122: 829-839.

51 Mantzoros CS, Flier JS. Leptin as a therapeutic agent - trials and tribulations. J Clin Endocrinol Metab 2000; 85: 4000-4002.

52 Tankersley CG, O'Donnell C, Daood MJ. Leptin attenuates respiratory complications associated with the obese phenotype. J Appl Physiol 1998; 85: 2261-2269.

53 O'Donnell CP, Schaub CD, Haines AS, et al. Leptin prevents respiratory depression in obesity. Am J Respir Crit Care Med 1999; 159: 1477-1484.

54 Yamauchi T, Kamon J, Waki H, et al. The fat-derived hormone adiponectin reverses insulin resistance associated with both lipoatrophy and obesity. Nat Med 2001; 7: 941-946.

55 Weyer C, Funahashi T, Sonnenberg G, et al. Hypoadiponectinemia in obesity and type 2 diabetes: close 
association with insulin resistance and hyperinsulinemia. J Clin Endocrinol Metab 2001; 86: 1930-1935.

56 Staiger H, Tschritter O, Machann J, et al. Relationship of serum adiponectin and leptin concentrations with body fat distribution in humans. Obes Res 2003; 11: 368-372.

57 Beltowski J. Adiponectin and resistin - new hormones of white adipose tissue. Med Sci Monit 2003; 9: 55-61.

58 Spranger J, Kroke A, Mohlig M, et al. Adiponectin and protection against type 2 diabetes mellitus. Lancet 2003; 18: 226-228.

59 Harsch IA, Wallaschofski H, Koebnick C, et al. Adiponectin in patients with obstructive sleep apnoea syndrome: course and physiological relevance. Respiration 2004; 71: 580-586.

60 Wolk R, Svatikova A, Nelson CA, et al. Plasma levels of adiponectin, a novel adipocyte-derived hormone, in sleep apnoea. Obesity Research 2005; 13: 186-190.

61 Zhang X-L, Yin K-S, Wang H, Su S. Serum adiponectin levels in adult male patients with obstructive sleep apnoea hypopnoea syndrome. Respiration 2006; 73: 73-77.

62 Makino S, Handa H, Suzukawa K, et al. Obstructive sleep apnoea syndrome, plasma adiponectin levels, and insulin resistance. Clin Endocrinol (Oxford) 2006; 64: 12-19.
63 Pepperell JCT, Ramdassingh-Dow S, Crosthwaite N, et al. Ambulatory blood pressure after therapeutic and subtherapeutic nasal continuous positive airway pressure for obstructive sleep apnoea. A randomized parallel trial. Lancet 2001; 359: 204-210.

64 Chalmers J, MacMahon S, Mancia G, et al. 1999 World Health Organization - International Society of Hypertension Guidelines for the management of hypertension. Guidelines sub-committee of the World Health Organization. Clin Exp Hypertens 1999; 21: 1009-1060.

65 Yaneko Y, Floras JS, Usui K, et al. Cardiovascular effects of continuous positive airway pressure in patients with heart failure and obstructive sleep apnoea. N Engl J Med 2003; 348: 1233-1241.

66 Milleron O, Pilliere R, Foucher A, et al. Benefits of obstructive sleep apnoea treatment in coronary artery disease: a long-term follow-up study. Eur Heart J 2004; 25: 728-734.

67 Marin JM, Carrizo SJ, Vicente E, Agusti AG. Long-term cardiovascular outcomes in men with obstructive sleep apnoea-hypopnoea with or without treatment with continuous positive airway pressure: an observational study. Lancet 2005; 365: 1046-1053. 